\title{
BMJ Open Application of the theory of regulatory fit to promote adherence to evidence- based breast cancer screening recommendations: experimental versus longitudinal evidence
}

\author{
Serena Petrocchi (1) , ${ }^{1}$ Ramona Ludolph, ${ }^{1}$ Nanon H M Labrie, ${ }^{2}$ Peter Schulz ${ }^{1}$
}

To cite: Petrocchi S, Ludolph R, Labrie NHM, et al. Application of the theory of regulatory fit to promote adherence to evidence-based breast cancer screening recommendations: experimental versus longitudinal evidence. BMJ Open 2020;10:e037748. doi:10.1136/ bmjopen-2020-037748

- Prepublication history and additional materials for this paper is available online. To view these files, please visit the journal online (http://dx.doi. org/10.1136/bmjopen-2020037748).

Received 18 February 2020 Revised 09 September 2020 Accepted 29 September 2020

A) Check for updates

(c) Author(s) (or their employer(s)) 2020. Re-use permitted under CC BY. Published by BMJ.

${ }^{1}$ Institute of Communication \& Health, Università della Svizzera italiana, Lugano, Switzerland

${ }^{2}$ Athena Institute, Vrije Universiteit Amsterdam, Amsterdam, The Netherlands

Correspondence to Dr Serena Petrocchi; serena.petrocchi@usi.ch

\section{ABSTRACT}

Objectives To reduce overtreatment caused by overuse of screening, it is advisable to reduce the demand for mammography screening outside the recommended guidelines among women who are not yet eligible for inclusion in systematic screening programmes. According to principles of regulatory fit theory, people make decisions motivated by either orientation to achieving and maximising gains or avoiding losses. A study developed in two phases investigated whether video messages, explaining the risks and benefits of mammography screening for those not yet eligible, are perceived as persuasive

Design Phase 1 was an experimental study in which women's motivation orientation was experimentally induced and then they were exposed to a matching video message about mammography screening. A control group received a neutral stimulus. Phase 2 introduced a longitudinal component to study 1 , adding a condition in which the messages did not match with the group's motivation orientation. Participants' natural motivation orientation was measured through a validated questionnaire

Participants 360 women participated in phase 1 and another 292 in phase 2. Participants' age ranged from 30 to 45 years, and had no history of breast cancer or known BReast CAncer gene (BRCA) 1/2 mutation.

Results In phase 1, a match between participants' motivation orientation and message content decreased the intention to seek mammography screening outside the recommended guidelines. Phase 2, however, did not show such an effect. Fear of breast cancer and risk perception were significantly related to intention to seek mammography screening

Conclusions Public health researchers should consider reducing the impact of negative emotions (ie, fear of breast cancer) and risk perception when promoting adherence to evidence-based breast cancer screening recommendations.

\section{INTRODUCTION}

Breast cancer is one of the most common forms of cancer in women worldwide and the principal cause of cancer-related death

\section{Strengths and limitations of this study}

- An experimental study (phase 1) and an experimental study with a longitudinal component (phase 2) were implemented applying principles from the theory of regulatory fit.

- An individual's goal-pursuit orientation was induced in phase 1 through a priming technique, and measured through a validated questionnaire in phase 2 .

- Messages were tailored to create a match (or not) between message content and the individual's goalpursuit orientation.

- Limitations of the studies included dropout rates (phase 2) and selection bias (due to cancer fear).

in the female population. ${ }^{1}$ To promote early diagnosis, many EU countries have introduced systematic breast cancer screening programmes. ${ }^{2}$ However, the age threshold to start inviting women to screening is in dispute. ${ }^{3-5}$ The balance between the benefits (ie, reducing breast cancer mortality) and the harm associated with mammography (ie, X-ray exposure, overdiagnosis and false positive results; see ${ }^{4-8}$ ) is less certain for women aged under 50. Technologies for breast cancer screening have been constantly evolving, affecting evidence quality and suggested recommendations. ${ }^{9}$ For these reasons recommended age for starting screening have varied from $40^{10}$ to $45^{1112}$ to 50 years. ${ }^{13} 14$

In the last years, there has been a vast amount of research on screen intention, including barriers, enablers and how to get women with characteristics matching with the recommended guidelines to adhere to the screening programmes, ${ }^{15-17}$. There was also a progressive shift from persuading women to undergo screening to increasing their informed decision making. ${ }^{18}$ Targeted information programmes and invitation materials 
encouraging women to learn about the screening procedures increased levels of knowledge and supported decision making about their participation. ${ }^{19} 20$ Web-based dynamic decision aids, including pros, cons, controversies and overdiagnosis-overtreatment issues, have been found to improve the quality of information without reducing the screening participation rate. ${ }^{21}$

Other research tested communication programmes intending to inform women approaching 70 years of age about the benefits and harms of continuing screening. ${ }^{2223}$ Similarly, non-high-risk women below the recommended age threshold seek and receive mammography screenings outside the suggested guidelines in the USA, ${ }^{24}{ }^{25}$ Switzerland, ${ }^{26}{ }^{27}$ Germany ${ }^{28}$ and The Netherlands. ${ }^{29}$ Studies show that women tend to overestimate the mortality reduction determined by breast cancer screening, ${ }^{30} 31$ and that they have unrealistic expectations regarding screening as reducing the risk of breast cancer ${ }^{32}$ Moreover, social pressure in favour of breast cancer screening may stimulate a sense of moral obligation to participate ${ }^{33} 34$ even among young women.

Given the above-mentioned considerations, women under the age threshold for systematic breast cancer screening may consider the recommendation to avoid screening as counterintuitive, although scientifically supported, because of social pressure and the belief that cancer screening can save lives. The present research aimed to promote adherence to evidence-based recommendations on breast cancer screening among young women by activating a motivation system, such as regulatory orientation. ${ }^{35}$

\section{THEORY OF REGULATORY FIT}

According to a popular psychological theory proposed by, ${ }^{36}$ people show one of two regulatory orientations, which determines how they pursue their goals. They either show a promotion-focused orientation, meaning they eagerly strive towards the realisation of desired outcomes, or they show a prevention-focused orientation, emphasising the prevention of errors and losses and making them safety driven. ${ }^{36}{ }^{37}$ While every individual has a natural tendency to lean more towards one orientation than the other, thus making it a measurable trait, ${ }^{38}$ the regulatory orientation can also be experimentally induced..$^{35639}$

If individuals adopt a behaviour or processes a message highlighting goal-pursuit strategies that match their regulatory orientation, they experience a phenomenon called 'regulatory fit'. ${ }^{35}$ For example, if a person with a promotion orientation reads a message highlighting strategies to achieve gains, a fit condition occurs. The same applies to someone with a prevention orientation processing a message emphasising strategies to avoid losses. Such a fit or match causes an 'it just feels right' perception, increasing the perceived value of the behaviour. ${ }^{40}$

The application of regulatory fit in the area of health communication is beneficial across various health contexts and outcomes. ${ }^{41}$ Regulatory fit has been consistently found to influence outcomes such as evaluation, behaviour and behavioural intention. ${ }^{42}$ Some authors ${ }^{40}$ showed that this 'it-just-feels-right' experience is also transferred to the context of persuasion, with positive effect of regulatory fit on the perceived persuasiveness of a message. A study by Uskul et $a t^{43}$ in the context of tobacco use prevention among adolescents is in line with this finding. The effects of regulatory fit have also been extensively studied in the context of disease prevention and health promotion. ${ }^{44}{ }^{45}$ In particular, some authors ${ }^{43}$ applied the principles of regulatory fit to inform people about the benefits of regular cancer screenings. A systematic review ${ }^{41}$ finds that the use of the principle of regulatory fit has the potential to increase the effectiveness of health communication across a range of health contexts and outcomes, making it a promising tool for tackling the problem of unwarranted demand for mammography screening outside the recommended guidelines.

No previous studies have tested messages designed according to the assumptions of regulatory fit to influence the intention to not engage in disease detection screening. This would challenge the intuitive perception that breast cancer screening leads to a mortality reduction determined by breast cancer in women over the age of $50,{ }^{3031}$ and the unrealistic expectations regarding screening as reducing the risk of breast cancer. ${ }^{32}$ The purpose of the present research was to test whether health messages framed to correspond with a woman's regulatory orientation are effective in reducing the intention to ask for breast cancer screening in non-high-risk women under the age of 45, according to the local mammography screening guidelines. The following hypotheses have been tested:

HP1: a fit between the message frame and the regulatory orientation would lead to an immediate reduction of the intention to ask for breast cancer screening, in nonhigh-risk women under the age threshold indicated by the local guidelines.

HP2: a fit between the message frame and the regulatory orientation would lead to a reduction of the intention to ask for breast cancer screening, stable over time.

To this end, a study has been developed organised in two distinct phases: Phase 1 was an experimental study testing HP1, while phase 2 added a longitudinal component and tested HP2.

\section{METHODS \\ Participants}

Phase 1

An a priori power analysis applying $\mathrm{G}^{*}$ Power V.3.1.9.2, ${ }^{46}$ estimated a sample of 249 participants $(\alpha=0.05, d=0.95$, $\eta^{2}=0.05$; see reference 41 ). Participants living in the Italian speaking, Swiss canton of Ticino completed an online survey from June to September 2016. The research was repeatedly advertised on the Facebook page of the University. Exclusion criteria were: a personal history of breast cancer, BRCA mutations, insufficient fluency in 
Italian. The survey required women to answer each question before progressing to the next screen; as such there were no missing data. Participants received a $10 \mathrm{CHF}$ supermarket voucher for their participation in phase 1 . Before starting the questionnaire, participants completed a written informed consent by clicking on the corresponding button (ie, 'yes, I want to participate'; 'no, I do not want to participate').

Five hundred women from 30 to 45 years started the survey: 121 (16\%) initiated the pretest questionnaires but dropped out. Nineteen of the women were excluded from the final sample because they did not complete the experimental manipulation. No differences emerged in the pretest variables between those who filled in only the pretest $(\mathrm{N}=140)$ and who filled in the entire survey $(\mathrm{N}=360)$. Participants were randomly assigned to prevention fit, promotion fit and control condition (see table 1). No differences were found between the intervention groups and the control group on sociodemographic variables.

\section{Phase 2}

A priori power analysis estimated a sample size of 312 . Recruitment took place from June to October 2017. The research was advertised through the Facebook page of the University and by RCSMedia Group, an Italy-based publishing group that uses participant panels. Inclusion/ exclusion criteria were as for phase 1, with the addition that participants included in phase 1 could not participate in phase 2. Participants completed a written informed consent as for phase 1 , and at the end received a 10 Swiss Francs /Euros supermarket voucher.

A total of 973 women aged from 30 to 45 filled in the pretest questionnaires (ie, pretest sample). Completed questionnaires (ie, analytical sample) were returned by 292 women with an attrition rate of $70 \%$. Comparisons between the pretest sample and the analytical sample did not yield significant differences. A total of 292 women participated in the research (see table 1). This time, women aged 30-45 living in Ticino and Italy participated. Italian and Ticino-Swiss participants are not only comparable from a cultural and linguistic point of view, but also screening guidelines in Ticino and Italy are alike, inviting 50-74yeas old biennially for mammography screening. No differences were found among the five groups regarding sociodemographic variables or other pretest variables.

\section{Process, measures and data collection \\ Phase 1}

A pretest and post-test design with two experimental conditions and a control group was applied (see figure 1 for full details).

At pretest, the survey included measures of health status and health behaviours, a set of questions on past diagnosis of breast cancer, mammography, biopsy and knowledge of the Ticino screening programme. Women were rated on their fear of breast cancer, level of involvement in breast cancer and confidence in the benefit of mammography (see online supplemental material).

Participants were randomly assigned into a promotion fit, prevention fit or control condition. Regulatory priming manipulation was then induced following, ${ }^{47}$ procedure (see online supplemental material). In the fit conditions, immediately after priming, the participants watched a video-message highlighting goal-pursuit strategies matching with the primed focus (see online supplemental material). The control group received a leaflet without any prompt for the regulatory orientation (see online supplemental material). In a pilot study, 30 women assessed the survey as clear and understandable.

\section{Phase 2}

A pretest and post-test longitudinal design was applied with four experimental conditions, two fit conditions (promotion and prevention), two non-fit conditions (promotion and prevention) and a control group (see figure 2).

In the pretest (T0), participants replied to the same questions as for phase 1 (see online supplemental material). In phase 2, the regulatory focus orientation was measured with a questionnaire (see online supplemental material), rather than induced as in phase 1 , because working with the trait regulatory focus would be more stable than a primed focus in a longitudinal design. Women were then identified according to their goal-pursuit main orientation (prevention orientation vs promotion orientation). Subsequently, participants were randomly assigned to the fit or non-fit condition or control group. In other words, randomisation was performed separately for preventionoriented women and promotion-oriented women to ensure a balanced representation of orientations between the match and non-match conditions. Participants in the fit conditions watched two videos (at T1 and T2) emphasising the fit concerns (see online supplemental material). In the non-fit conditions, participants watched two videos (at T1 and T2) emphasising the non-fit concerns (see online supplemental material). In the control group, participants watched two videos (at T1 and T2) treating the topic of breast cancer prevention, but without any regulatory prompt (see online supplemental material).

A post-test questionnaire evaluated the women's intention to ask for opportunistic screening (T3). Ten days elapsed between each experimental phase. Three women from the general population assessed the videos as comprehensible and clear. The final survey was tested by fifteen women aged $30-45$, who assessed it as clear and comprehensible.

\section{Patient and public involvement \\ Phase 1 and phase 2}

Results from previous studies involving participants from Switzerland informed the present research (see reference 27). Participants were not directly involved in the design, conduct, recruitment, reporting or dissemination of the study results. An expert panel, composed of two health 


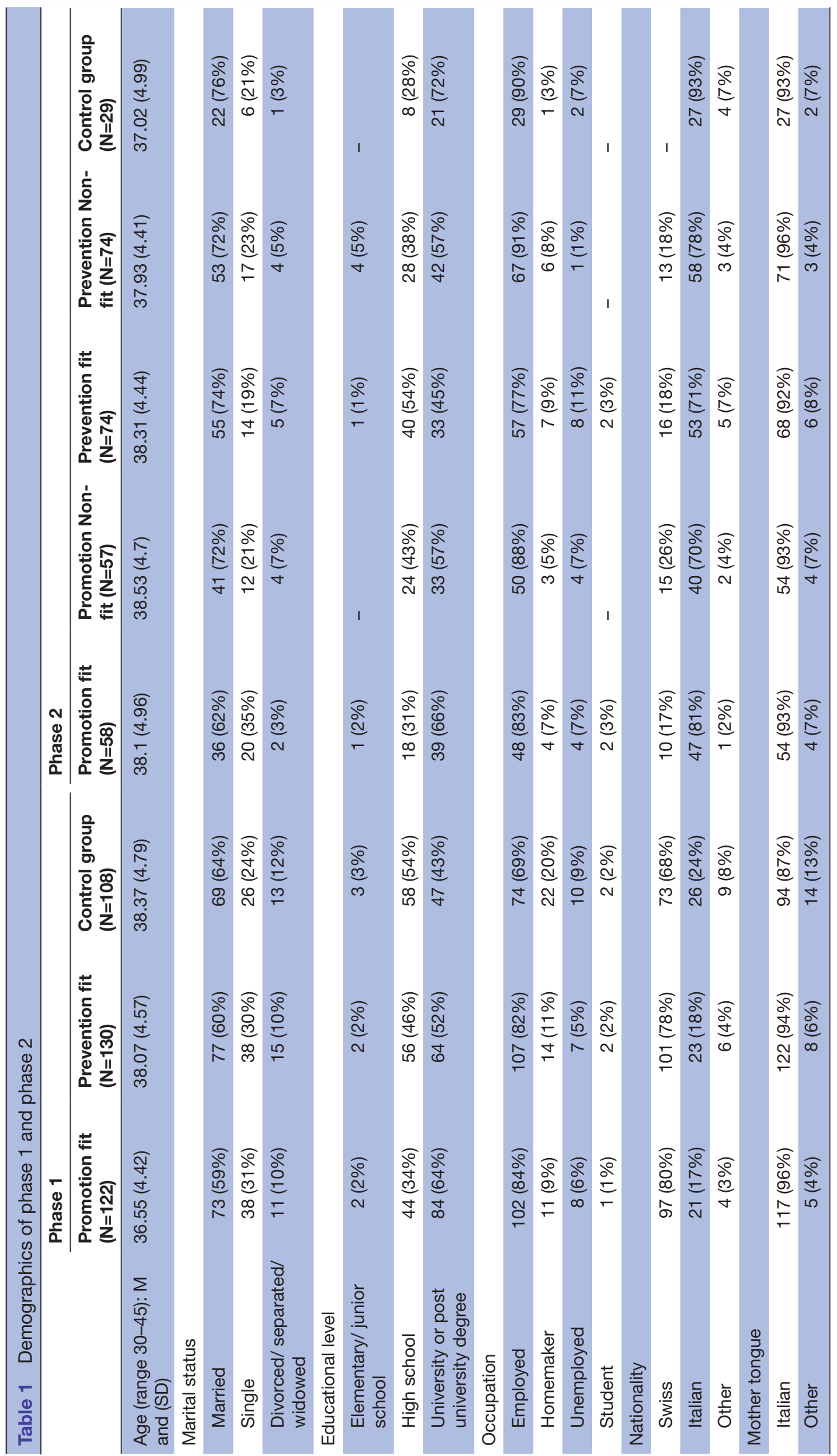




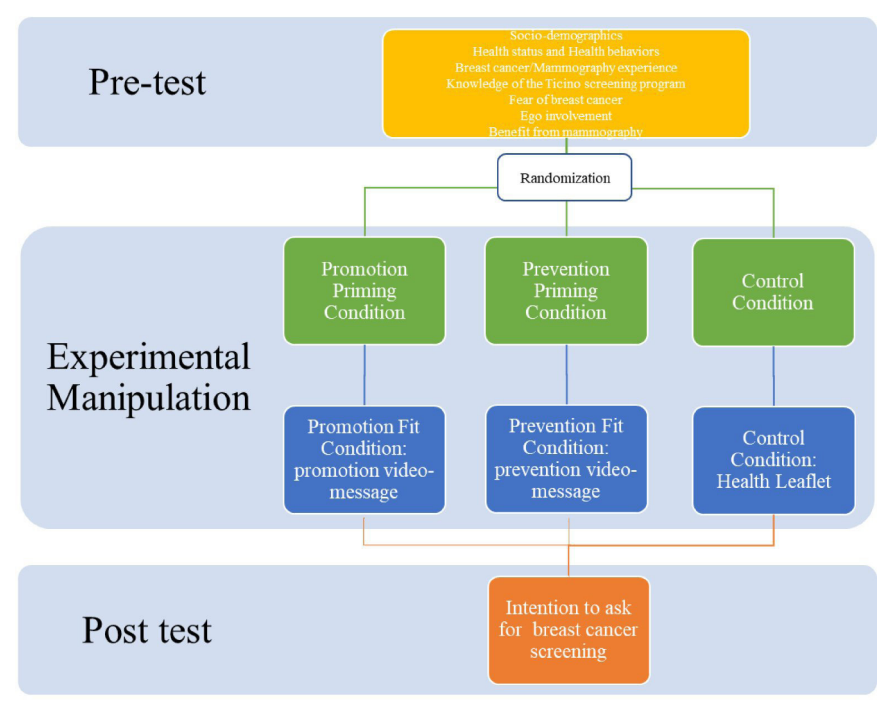

Figure 1 Flow chart of the study 1.

communication professionals with expertise on regulatory fit theory, evaluated the message contents and the graphical aspects of the videos.

\section{Analytic strategy}

Phase 1 and phase 2

In both phase 1 and phase 2, data were normalised through reverse scoring and logarithmic transformations and there were no missing data.

In phase 1, an analysis of covariance (ANCOVA) tested the main hypothesis (HP1) of the study. The fit versus control conditions variable was inserted as independent variable. All the variables measured at the pretest were inserted as covariates. $\chi^{2}$ tests were conducted to evaluate whether the covariates might interact with the three experimental conditions in determining the intention to ask for breast cancer screening.
In phase 2, a repeated measure ANCOVA tested the main hypothesis (HP2) of the study. The fit versus nonfit versus control conditions variable was inserted as independent variable. All the variables measured at the pretest were inserted as covariates.

\section{RESULTS}

\section{Phase 1}

The ANCOVA analysis revealed that women in the two experimental conditions showed less intention to ask for breast cancer screening compared with the women in the control condition. Thus, when there is a fit between individual orientation (ie, a tendency to promote positive expected outcomes or to prevent negative outcomes for one's health) and the given message, then a persuasive effect is induced. There was no meaningful difference between the two manipulation conditions. Older women and women with higher levels of fear of breast cancer showed a greater intention to ask for breast cancer screening than younger ones and those with lower levels of fear. This evidence supports the assumption that regulatory orientation represents a motivational system able to overcome the impact of negative emotions and strengthen an individual's involvement in decisionmaking orientation. Descriptive data and results from the ANCOVA are displayed in table 2.

Further analyses were conducted to evaluate whether the covariates might interact with the three experimental conditions in determining the intention to ask for breast cancer screening. Analyses revealed only one association among the three groups of women and the past diagnoses of breast cancer among first degree-relatives, $\chi^{2}(2)=12.98$, $\mathrm{p}=0.002$. Women in the promotion fit condition had a lower number of breast cancer diagnoses among firstdegree relatives than was expected $(z=-1.96)$, while

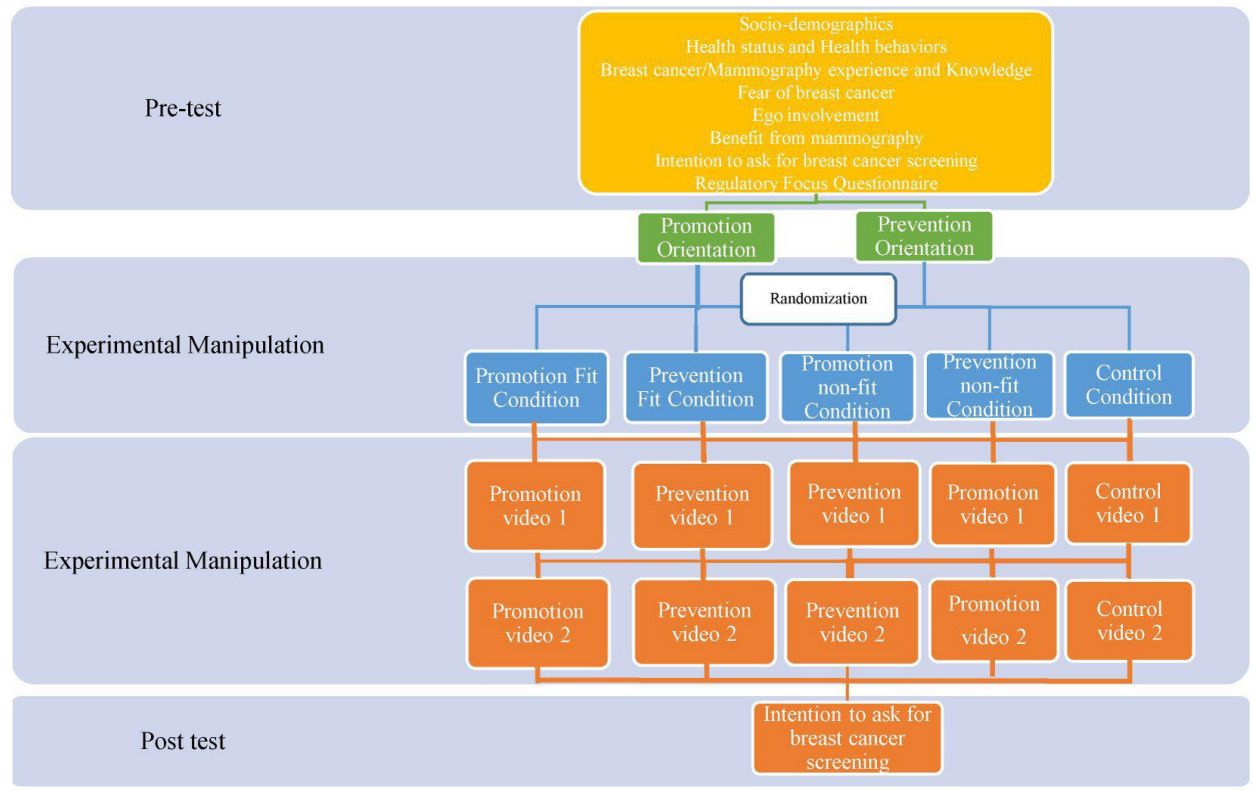

Figure 2 Flow chart of the study 2. 
Table 2 Descriptive statistics of the pretest and post-test variables with frequencies (\% frequencies between brackets) or means (SD between brackets), and results of the analyses

\begin{tabular}{|c|c|c|c|c|c|c|c|c|}
\hline & \multicolumn{3}{|l|}{ Phase 1} & \multicolumn{5}{|l|}{ Phase 2} \\
\hline & Promotion fit & Prevention fit & Control group & Promotion fit & Promotion non-fit & Prevention fit & Prevention non-fit & Control group \\
\hline \multicolumn{9}{|l|}{ Pretest variables } \\
\hline General health status & $3.88(0.77)$ & $3.77(0.87)$ & $3.7(0.87)$ & $3.79(0.79)$ & $3.63(0.67)$ & $3.66(0.76)$ & $3.70(0.77)$ & $3.76(0.69)$ \\
\hline Physical activity & $2.45(1.85)$ & $2.47(1.69)$ & $2.43(1.92)$ & $0.78(0.42)$ & $0.81(0.39)$ & $0.76(0.46)$ & $0.72(0.45)$ & $0.86(0.35)$ \\
\hline Smoking habits & $1.86(4.85)$ & $1.99(4.99)$ & $3.32(6.42)$ & $3.53(5.4)$ & $3.12(4.66)$ & $4.93(5.59)$ & $3.19(5.15)$ & $7.22(5.4)$ \\
\hline Alcohol consumption & $1.92(2.79)$ & $1.71(2.27)$ & $1.42(2.14)$ & $3(2.26)$ & $2.66(2.15)$ & $3.27(4.13)$ & $2.67(3.54)$ & $3.1(4)$ \\
\hline Fear of breast Cancer & $3.4(.85)$ & $3.4(.81)$ & $3.4(1)$ & $3.75(.95)$ & $3.59(.91)$ & $3.79(.95)$ & $3.83(.93)$ & $3.68(1)$ \\
\hline Ego-involvement & $5.9(1.1)$ & $5.8(1.27)$ & $5.9(1.3)$ & - & - & - & - & - \\
\hline $\begin{array}{l}\text { Benefit for } \\
\text { mammography }\end{array}$ & $3.9(0.62)$ & $3.8(0.62)$ & $4(0.74)$ & $4.1(0.75)$ & $4.12(0.73)$ & $4.16(0.68)$ & $4.16(0.65)$ & $3.94(0.78)$ \\
\hline $\begin{array}{l}\text { Intention to ask for BC } \\
\text { screening }\end{array}$ & - & - & - & $3.35(1.33)$ & $3.35(1.29)$ & $3.44(1.22)$ & $3.31(1.40)$ & $3.45(1.41)$ \\
\hline \multicolumn{9}{|l|}{ Diet } \\
\hline No & $46(38 \%)$ & $49(37 \%)$ & $39(36 \%)$ & $24(41 \%)$ & $30(53 \%)$ & 29 (39\%) & 27 (37\%) & $13(45 \%)$ \\
\hline Yes & 76 (62\%) & $81(62 \%)$ & 69 (64\%) & 34 (59\%) & 27 (47\%) & 45 (61\%) & 47 (63\%) & $16(55 \%)$ \\
\hline \multicolumn{9}{|l|}{$\mathrm{BC}$ among relatives } \\
\hline No & 117 (96\%) & 117 (90\%) & $89(82 \%)$ & 52 (90\%) & 48 (84\%) & 65 (88\%) & 67 (90\%) & 28 (97\%) \\
\hline Yes (mother) & $4(3 \%)$ & $8(6 \%)$ & 17 (16\%) & $5(9 \%)$ & $6(11 \%)$ & $7(10 \%)$ & $7(10 \%)$ & $1(3 \%)$ \\
\hline Do not know & $1(1 \%)$ & $5(4 \%)$ & $2(2 \%)$ & $1(1 \%)$ & $3(5 \%)$ & $2(2 \%)$ & - & - \\
\hline \multicolumn{9}{|l|}{ Mammography } \\
\hline No & 100 (82\%) & 100 (77\%) & 72 (67\%) & 40 (69\%) & 38 (67\%) & $50(68 \%)$ & 50 (68\%) & 23 (79\%) \\
\hline Yes & 22 (18\%) & $30(23 \%)$ & $36(33 \%)$ & $18(31 \%)$ & $19(33 \%)$ & $24(32 \%)$ & $24(32 \%)$ & $6(21 \%)$ \\
\hline \multicolumn{9}{|l|}{ Biopsy } \\
\hline No & 17 (77\%) & 27 (90\%) & $26(72 \%)$ & 57 (98\%) & 55 (97\%) & 67 (91\%) & 71 (96\%) & 29 (100\%) \\
\hline Yes & $5(23 \%)$ & $3(10 \%)$ & $10(28 \%)$ & $1(2 \%)$ & $2(3 \%)$ & $7(9 \%)$ & $3(4 \%)$ & - \\
\hline \multicolumn{9}{|c|}{ Knowledge of BC screening programme } \\
\hline No & $76(62 \%)$ & $69(53 \%)$ & 64 (59\%) & $21(36 \%)$ & $23(40 \%)$ & 26 (35\%) & 27 (37\%) & $7(24 \%)$ \\
\hline Yes & $46(38 \%)$ & $61(47 \%)$ & $44(41 \%)$ & 37 (64\%) & $34(60 \%)$ & 48 (65\%) & 47 (63\%) & 22 (76\%) \\
\hline \multicolumn{9}{|c|}{ Knowledge of the age thresholds for BC screening programme } \\
\hline Do not know & $16(35 \%)$ & $24(39 \%)$ & $13(30 \%)$ & $21(36 \%)$ & $32(56 \%)$ & $26(35 \%)$ & $27(37 \%)$ & $7(24 \%)$ \\
\hline Wrong & $22(48 \%)$ & $28(46 \%)$ & $30(68 \%)$ & $29(50 \%)$ & $18(32 \%)$ & $34(46 \%)$ & $37(50 \%)$ & $18(62 \%)$ \\
\hline Correct & $8(17 \%)$ & $9(15 \%)$ & $1(2 \%)$ & $8(14 \%)$ & $7(12 \%)$ & $14(19 \%)$ & $10(13 \%)$ & $14(14 \%)$ \\
\hline \multicolumn{9}{|l|}{ Post-test variables } \\
\hline $\begin{array}{l}\text { Intention to ask for BC } \\
\text { screening }\end{array}$ & $2.20(1.05)$ & $2.26(1.06)$ & $3.36(1.33)$ & $3.02(1.61)$ & $2.89(1.48)$ & $3.17(1.48)$ & $3(1.54)$ & $2.78(1.49)$ \\
\hline \multirow[t]{7}{*}{$\begin{array}{l}\text { Results from ANCOVA* } \\
\text { or repeated measures } \\
\text { ANCOVA† }\end{array}$} & \multicolumn{3}{|c|}{$F^{\star}(2,319)=49.57, p<0.0001, \eta_{p}^{2}=0.24$} & \multicolumn{5}{|c|}{$\begin{array}{l}\text { Within subject comparison between preintention and postintention: } \mathrm{F} \dagger(1,267.91)=5.10 \text {, } \\
p=0.025 \text {, partial } \eta^{2}=0.02 \\
\text { Between subject comparisons among groups: } \mathrm{F} \dagger(4,284)=0.43, p>0.05\end{array}$} \\
\hline & \multicolumn{8}{|c|}{$\begin{array}{l}\text { Promotion fit versus control condition } \\
\mathrm{t}(319)=-8.80, \mathrm{p}<0.0001, r=0.44\end{array}$} \\
\hline & \multicolumn{8}{|c|}{$\begin{array}{l}\text { Prevention fit versus control condition } \\
t(319)=-8.80, p<0.0001, r=0.44\end{array}$} \\
\hline & \multicolumn{8}{|c|}{ Significant covariates } \\
\hline & \multirow{3}{*}{\multicolumn{3}{|c|}{$\begin{array}{l}\text { Fear of } B C: F(1,319)=6.81, p=0.010 \text {, partial } \\
\eta_{p}^{2}=0.02 \\
\text { Age: } F(1,319)=26.20, p<0.0001 \text {, partial } \eta_{p}^{2}=0.08\end{array}$}} & \multicolumn{5}{|c|}{$\begin{array}{l}\text { Fear of } \mathrm{BC}: \mathrm{t}(284)=2.76, \mathrm{p}=0.006, \mathrm{~B}=0.24 \text {, partial } \eta^{2}=0.03(95 \% \text { low } \mathrm{Cl}=0.07,95 \% \text { high } \\
\mathrm{Cl}=0.42)\end{array}$} \\
\hline & & & & \multicolumn{5}{|c|}{ Age, $\mathrm{t}(284)=6.26, \mathrm{p}<0.0001, \mathrm{~B}=0.11$, partial $\eta^{2}=0.12(95 \%$ low $\mathrm{Cl}=0.08,95 \%$ high $\mathrm{Cl}=0.15)$} \\
\hline & & & & \multicolumn{5}{|c|}{$\begin{array}{l}\text { Risk perception, } \mathrm{t}(284)=2.26, \mathrm{p}=0.024, \mathrm{~B}=0.37 \text {, partial } \eta^{2}=0.02(95 \% \text { low } \mathrm{Cl}=0.05,95 \% \text { high } \\
\mathrm{Cl}=0.70) \text {. }\end{array}$} \\
\hline
\end{tabular}

${ }^{*}$ Ancova

†Repeated Measures Ancova

ANCOVA, analysis of covariance; BC, breast cancer. 
women in the control condition had a higher number than expected $(z=2.8)$. The subsequent ANCOVA did not find any significant interaction between past diagnosis of breast cancer among first-degree relatives and the experimental manipulations, therefore, demonstrating that the regulatory fit genuinely influences the intention.

\section{Phase 2}

There was a general significant decrease of the intention from pre-evaluation to postevaluation across groups, but no significant differences among them, indicating that the scores of the post-test intention among the five groups were in general the same. Among the covariates older women, greater fear of breast cancer and greater risk perception were associated with greater post-test intention compared with the opposite. Table 2 shows descriptive statistics and results from the analysis.

The intervention effect was not significant either when the two fit conditions and the two non-fit conditions were collapsed into two categories (ie, comparison among fit condition vs unfit condition vs control) as done in phase 1 , even though a general decrease in the postintention across groups was found as before. Risk perception was tested as a moderator, but the analysis was not significant.

\section{General discussion}

The present research shows inconsistent results. Phase 1 confirmed the hypothesised effect of the intervention on the intention to seek mammography screening before the age of 45 , with a reduction of the intention when a fit between the message frame and the individual's regulatory focus occurred. Longitudinal results from phase 2 demonstrated that this effect was not significant over 1 month, although a general decrease of the intention across groups was observed. Even though further evidence is needed to confirm our results, it still seems that the 'just-feels-right' experience appears to be insufficient to convince non high-risk women under the age threshold to avoid systematic breast cancer screening outside of the recommended guidelines.

Our results could genuinely reflect the fact that the regulatory fit is not sufficient to induce a long-term decrease in women's intentions or could be an artefact of the research itself. Phase 1 and phase 2 applied two different ways to evoke a regulatory orientation. Phase 1 primed the individuals' regulatory orientation, whereas phase 2 measured it with a questionnaire to overcome a limitation of phase 1 and explore a different aspect of the theory. One could argue that the different ways to induce versus measure the regulatory orientation could have influenced the persuasiveness of the message and so its effectiveness. However, researchers of regulatory orientation suggest that there is no difference between the two procedures. ${ }^{39}$ Therefore, we could exclude that the two methods have had a differential impact on posttest intention. Possible differences in the cultural milieu of Italian-speaking Swiss and Italian participants might make the population primed to receive or primed to ignore the intervention. However, to the best of our knowledge, there is no study comparing different cultural environments in the propensity to be primed or not.

The relatively small sample size and the recruitment strategies could have influenced the power of the analyses, the sample composition and, ultimately, the significance of the results. However, there is no such concern in phase 2 since the effect due to the intervention was not significant either when the two fit conditions and the two non-fit conditions were collapsed into two categories.

Finally, a variable might have moderated the association between intervention and intention. $\mathrm{As}^{48}$ demonstrated, individuals' consideration of future consequences of a particular behaviour influences the effectiveness of framing techniques in predicting risk perceptions, attitudes and behavioural intentions regarding health-related advertisements. In our research, the risk perception was tested as a moderator variable, but the analyses yielded no significant results.

Fear of breast cancer, age, and risk perception (only in phase 2) were significantly related to women's intentions. The predicting role of age is not surprising because, approaching the age of 50 , women are invited to undertake regular mammography screening in Ticino and in Italy. Risk perception and fear of breast cancer are the most sensitive variables. Breast cancer naturally evokes negative emotions. ${ }^{27}{ }^{49-51}$ Moreover, the benefits of mammography screening often seem to be overestimated. ${ }^{30}$ Therefore, it is challenging to develop effective health messages promoting the adherence to breast cancer screening guidelines for young women based on factual information. As messages based on the principles of regulatory fit take the motivational orientations of recipients into account, they go beyond the effectiveness of purely providing information. Here, messages building on the theory of regulatory fit did not seem to offer a new way to overcome the 'emotional barrier' generated by the fear of breast cancer. However, phase 2 demonstrated a general 'pedagogical effect' deriving from talking about the topic of breast cancer screening without evoking a boomerang effect (ie, an increase of intention instead of a decrease).

The present research has several limitations. We experienced high dropout rates, especially in phase 2. The high drop-out rates may be related to the topic of breast cancer itself or the fear associated with it. One could assume that women with a low level of fear of breast cancer may have decided not to take part in our research, and this may have created a selection bias that could affect the generalisability of the results. A second limitation concerns the fact that we measured the intention to ask for breast cancer screening, not the actual behaviour. Although according to many theories in the field of health promotion (eg, Health Belief Model), the intention is a valid predictor of the actual behaviour, it would be beneficial if future research followed women until the moment they actually have a mammography.

In conclusion, it seems that by framing health messages that conform to a promotion or prevention focus, a decrease in the intention to ask for merely preventive opportunistic mammography screening is observed; but this takes place only immediately after message exposure. The influence decreases over time, and the messages lose their predictive 
effects after 1 month. This may be because breast cancer fear/ opinions are very deeply ingrained in women and one/two messages cannot change that. Accordingly, possibly results from phase 1 are valid, but repeated exposure to more than one regulatory fit message is needed to change viewpoints in the long term.

Even though our results only partially confirmed our hypothesis, there are substantial implications for future research. The results demonstrate that fear of breast cancer and risk perception are the main challenges to face in order to promote adherence to evidence-based recommendations on breast cancer screening. Public health researchers must investigate what factors may increase the effectiveness of health information. According to our evidence, future research may consider understanding how to reduce the impact of negative emotions rather than try to overcome their effect. For example, a research ${ }^{52}$ found that humour in health messages reduces the anxiety associated with performing cancer screening. Humour may be implemented in health messages aimed to promote evidence-based breast cancer screening recommendations. Reducing the number of unnecessary breast cancer screenings would thus allow the prevention of avoidable false positive and false negative diagnoses and unjustifiable mental and physical suffering for women. In the long term, this would also enable policymakers and health professionals to allocate scarce resources for disease prevention, detection and treatment in a more effective way.

Acknowledgements We are very grateful to Professor John Hodgson for his thoughtful revisions.

Contributors SP and RL drafted the first version of the manuscript. All authors contributed to writing and critically revising it and approved its final version. PS acquired funding. NHML, PS and RL designed study 1 and prepared the materials. PS, SP and RL designed study 2 and prepared the materials. SP and RL collected data for study 1 . SP collected data for study 2 . SP performed the analyses for study 1 and study 2 .

Funding This work was supported by the Swiss National Science Foundation (grant number FNS 100019-153131/1).

Competing interests None declared.

Patient consent for publication Not required.

Ethics approval The University's Ethical Committee approved phase 1 and phase 2.

Provenance and peer review Not commissioned; externally peer reviewed.

Data availability statement No data are available. Data are available on request.

Supplemental material This content has been supplied by the author(s). It has not been vetted by BMJ Publishing Group Limited (BMJ) and may not have been peer-reviewed. Any opinions or recommendations discussed are solely those of the author(s) and are not endorsed by BMJ. BMJ disclaims all liability and responsibility arising from any reliance placed on the content. Where the content includes any translated material, BMJ does not warrant the accuracy and reliability of the translations (including but not limited to local regulations, clinical guidelines, terminology, drug names and drug dosages), and is not responsible for any error and/or omissions arising from translation and adaptation or otherwise.

Open access This is an open access article distributed in accordance with the Creative Commons Attribution 4.0 Unported (CC BY 4.0) license, which permits others to copy, redistribute, remix, transform and build upon this work for any purpose, provided the original work is properly cited, a link to the licence is given, and indication of whether changes were made. See: https://creativecommons.org/ licenses/by/4.0/.
ORCID iD

Serena Petrocchi http://orcid.org/0000-0002-7223-8240

\section{REFERENCES}

1 Torre LA, Islami F, Siegel RL, et al. Global cancer in women: burden and trends. Cancer Epidemiol Biomarkers Prev 2017;26:444-57.

2 Altobelli E, Lattanzi A. Breast cancer in European Union: an update of screening programmes as of March 2014 (review). Int J Oncol 2014;45:1785-92.

3 Bucchi L, Ravaioli A, Baldacchini F, et al. Annual mammography at age $45-49$ years and biennial mammography at age $50-69$ years: comparing performance measures in an organised screening setting. Eur Radiol 2019;29:5517-27.

4 Gøtzsche PC, Jørgensen KJ, Cochrane Breast Cancer Group. Screening for breast cancer with mammography. Cochrane Database Syst Rev 2013;156:CD001877.

5 van den Ende $\mathrm{C}$, Oordt-Speets AM, Vroling $\mathrm{H}$, et al. Benefits and harms of breast cancer screening with mammography in women aged 40-49 years: a systematic review. Int $J$ Cancer 2017:141:1295-306.

6 Armstrong K, Moye E, Williams S, et al. Screening mammography in women 40 to 49 years of age: a systematic review for the American College of physicians. Ann Intern Med 2007;146:516-26.

7 Barratt A, Howard K, Irwig L, et al. Model of outcomes of screening mammography: information to support informed choices. $B M J$ 2005;330:936-8.

8 Gøtzsche PC, Nielsen M. Screening for breast cancer with mammography. Cochrane Database System Rev 2006;4:CD001877.

9 Carter SM, Williams J, Parker L, et al. Screening for cervical, prostate, and breast cancer: interpreting the evidence. Am J Prev Med 2015;49:274-85.

10 Mainiero MB, Lourenco A, Mahoney MC, et al. ACR appropriateness criteria breast cancer screening. J Am Coll Radiol 2016;13:R45-9.

11 European Commission Initiative on Breast Cancer (ECIBC) Guideline. European guidelines on breast cancer screening and diagnosis, 2018. Available: https://healthcare-quality.jrc.ec.europa.eu/europeanbreast-cancer-guidelines/screening-ages-and-frequencies\#recsgroup-40-44

12 Oeffinger KC, Fontham ETH, Etzioni R, et al. Breast cancer screening for women at average risk: 2015 guideline update from the American cancer Society. JAMA 2015;314:1599-614.

13 Lauby-Secretan B, Scoccianti C, Loomis D, et al. Breast-cancer screening--viewpoint of the IARC Working Group. N Engl J Med 2015;372:2353-8.

14 Siu AL, U.S. Preventive Services Task Force. Screening for breast cancer: U.S. preventive services Task force recommendation statement. Ann Intern Med 2016;164:279-96.

15 Ahmad F, Cameron JI, Stewart DE. A tailored intervention to promote breast cancer screening among South Asian immigrant women. Soc Sci Med 2005;60:575-86.

16 Azaiza F, Cohen M. Health beliefs and rates of breast cancer screening among Arab women. J Womens Health 2006;15:520-30.

17 Payán DD, Maggard-Gibbons M, Flórez KR, et al. Taking care of yourself and your risk for breast cancer (CUIDARSE): a randomized controlled trial of a health communication intervention for Latinas. Health Educ Behav 2020;47:569-580.

18 Woloshin S, Schwartz LM, Black WC, et al. Cancer screening campaigns-getting past uninformative persuasion. N Engl J Med 2012;367:1677-9.

19 Kregting LM, van Ravesteyn NT, Spijker W, et al. Effects of a leaflet on breast cancer screening knowledge, explicit attitudes, and implicit associations. Patient Educ Couns 2020

20 Quaife SL, Ruparel M, Beeken RJ, et al. The lung screen uptake trial (LSUT): protocol for a randomised controlled demonstration lung cancer screening pilot testing a targeted invitation strategy for high risk and 'hard-to-reach' patients. BMC Cancer 2016;16:1-9.

21 Roberto A, Colombo C, Candiani G, et al. A dynamic web-based decision aid to improve informed choice in organised breast cancer screening. A pragmatic randomised trial in Italy. $\mathrm{Br} \mathrm{J}$ Cancer 2020;123:1-8.

22 Mathieu E, Barratt A, Davey HM, et al. Informed choice in mammography screening: a randomized trial of a decision aid for 70-year-old women. Arch Intern Med 2007;167:2039-46.

23 Smith J, Dodd RH, Hersch J, et al. Effect of different communication strategies about stopping cancer screening on screening intention and cancer anxiety: a randomised online trial of older adults in Australia. BMJ Open 2020;10:e034061. 
24 Block LD, Jarlenski MP, Wu AW, et al. Mammography use among women ages 40-49 after the 2009 U.S. preventive services Task force recommendation. J Gen Intern Med 2013;28:1447-53.

25 Kapp JM, Ryerson AB, Coughlin SS, et al. Racial and ethnic differences in mammography use among U.S. women younger than age 40. Breast Cancer Res Treat 2009;113:327-37.

26 Glaus A, Fäh B, Hornung R, et al. Das brustkrebspräventionsverhalten in Der Schweiz: AUS Der Perspektive von Frauen AUS drei Sprachregionen Der Schweiz. breast cancer prevention behaviour: a perspective of women from three language regions of Switzerland. Pflege 2004;17:385-94.

27 Labrie NHM, Ludolph RA, Schulz PJ. Mammography perceptions and practices among women aged 30-49: the role of screening programme availability and cultural affiliation. Patient Educ Couns 2020;103:369-75.

28 Klug SJ, Hetzer M, Blettner M. Screening for breast and cervical cancer in a large German City: participation, motivation and knowledge of risk factors. Eur J Public Health 2005;15:70-7.

29 Statistics Netherlands. Cbs: Ruim de helft van de vrouwen laat uitstrijkje maken. more than half of all women get a Pap-smear, 2015. Available: http://www.cbs.nl/nl-NL/menu/themas/gezondheidwelzijn/publicaties/artikelen/archief/2015/ruim-de-helft-van-devrouwen-laat-uitstrijkje-maken.htm

30 Chamot E, Perneger TV. Misconceptions about efficacy of mammography screening: a public health dilemma. J Epidemiol Community Health 2001;55:799-803.

31 Gigerenzer G, Mata J, Frank R. Public knowledge of benefits of breast and prostate cancer screening in Europe. J Natl Cancer Inst 2009;101:1216-20.

32 Domenighetti G, D’Avanzo B, Egger M, et al. Women's perception of the benefits of mammography screening: population-based survey in four countries. Int J Epidemiol 2003;32:816-21.

33 Parker L, Carter S, Williams J, et al. Avoiding harm and supporting autonomy are under-prioritised in cancer-screening policies and practices. Eur J Cancer 2017;85:1-5.

34 Willis K. Choice, trust and risk-the policy context and mammography screening. In: Mammography: recent advances. Croatia: InTech Publishers, 2012: 3-24.

35 Higgins ET. Making a good decision: value from fit. Am Psychol 2000;55:1217-30.

36 Higgins ET. Beyond Pleasure and pain. Am Psychol 1997;52:1280-300.
37 Keller PA. Regulatory focus and efficacy of health messages. Journal of Consumer Research 2006;33:109-14.

38 Higgins ET, Friedman RS, Harlow RE, et al. Achievement orientations from subjective histories of success: promotion pride versus prevention pride. Eur J Soc Psychol 2001;31:3-23.

39 Cesario J, Higgins ET, Scholer AA. Regulatory fit and persuasion: basic principles and remaining questions. Soc Personal Psychol Compass 2008;2:444-63.

40 Cesario J, Grant H, Higgins ET. Regulatory fit and persuasion: transfer from 'Feeling Right.'. J Pers Soc Psychol 2004;86:388-404.

41 Ludolph R, Schulz PJ. Does regulatory fit lead to more effective health communication? A systematic review. Soc Sci Med 2015;128:142-50.

42 Motyka S, Grewal D, Puccinelli NM, et al. Regulatory fit: a metaanalytic synthesis. J Consumer Psychol 2014;24:394-410.

43 Uskul AK, Keller J, Oyserman D. Regulatory fit and health behavior. Psychol Health 2008;23:327-46.

44 Zhao G, Pechmann $\mathrm{C}$. The impact of regulatory focus on adolescents' response to antismoking advertising Campaigns. $J$ Market Res 2007;44:671-87.

45 Spiegel S, Grant-Pillow H, Higgins ET. How regulatory fit enhances motivational strength during goal pursuit. Eur J Soc Psychol 2004;34:39-54.

46 Faul F, Erdfelder E, Lang A-G, et al. G*Power 3: a flexible statistical power analysis program for the social, behavioral, and biomedical sciences. Behav Res Methods 2007;39:175-91.

47 Freitas AL, Higgins ET. Enjoying goal-directed action: the role of regulatory fit. Psychol Sci 2002;13:1-6.

48 Kees J. Advertising framing effects and consideration of future consequences. J Consumer Affair 2011;45:7-32.

49 Consedine NS, Magai C, Krivoshekova YS, et al. Fear, anxiety, worry, and breast cancer screening behavior: a critical review. Cancer Epidemiol Biomarkers Prev 2004;13:501-10.

50 Hay JL, McCaul KD, Magnan RE. Does worry about breast cancer predict screening behaviors? A meta-analysis of the prospective evidence. Prev Med 2006;42:401-8.

51 Nekhlyudov L, Ross-Degnan D, Fletcher SW. Beliefs and expectations of women under 50 years old regarding screening mammography: a qualitative study. J Gen Intern Med 2003;18:182-9.

52 Nabi RL. Laughing in the face of fear (of disease detection): using humor to promote cancer self-examination behavior. Health Commun 2016;31:873-83. 